\title{
Information-based interventions for household water efficiency in England and Wales: Evidence, barriers and learning opportunities
}

\author{
Liang $\mathrm{Lu}^{*}$ \\ Centre for Fashion Business \& Innovation Research and Fashion Business School, London \\ College of Fashion, University of the Arts London, London WC1V 7EY, UK \\ Centre for Competition Policy, University of East Anglia, Norwich NR7 4TJ, UK \\ liang.lu@fashion.arts.ac.uk
}

October 2019

\begin{abstract}
Following the Department for Environment, Food \& Rural Affairs (Defra) of the UK's call in its recent Water Efficiency and Behaviour Change Rapid Evidence Assessment 2018, this paper seeks to understand the key barriers of conducting effective information-based interventions to encourage household water efficiency in England and Wales and the associated implications. We review the evidence of information provision to conserve water in England and Wales. We then set out the current key barriers, highlight what might have constituted to the barriers and, based on learnings from the literature, clarify some underlying confusion and suggest ways to improve.
\end{abstract}

Keywords: Behavioural intervention; Field experiment; Social norm; Water demand management; Water efficiency; Water conservation

JEL Classification: C93; D91; L95; Q25; Q28

\footnotetext{
*I thank Editor-in-Chief of the journal, Cecilia Tortajada, and an anonymous reviewer for their comments. I also thank David Deller, Morten Hviid, Danino Vittoria, Catherine Waddams, and workshop participants at the Lee Kuan Yew School of Public Policy, National University of Singapore. Any remaining errors are my own.
} 


\section{Introduction}

Population growth and climate change create uncertainty about the availability of water in the UK, and in some areas of southern England water stress is an increasing challenge. As of 201617, household demand accounted for about $55 \%$ of all water used in public supply in England and Wales; hence, it is crucial to encourage households to play their role in delivering a resilient water network (Ofwat, 2018). The UK's National Infrastructure Commission (2018) recommends reducing demand from the current average of 141 to 118 litres per person per day by 2050. Water companies in England and Wales have a legal duty to promote water efficiency, and they do so through different types of intervention.

Figure 1 outlines the price and non-price approaches that can be used individually or in combination to enhance water efficiency. Metering is grouped with tariffs under the price approach (e.g. Defra, 2018), because not all domestic premises are metered in the UK, and whether a water meter is fitted in may affect tariffs faced by households and decide the scope for price mechanisms to affect consumption. Metering as an intervention has received great endorsement, with House of Commons (2018) and National Infrastructure Commission (2018) recommending compulsory metering by all water companies. The challenges of using the other types of intervention under the price approach to encourage water saving, such as price increase, taxation, and in particular innovative Increasing Block Tariffs, are discussed in Lu et al. (2019).

This paper focuses on non-price information-based interventions and the relevant experience of water companies in England and Wales, which, as will be discussed later, appear to have been conflated with some technology-based interventions.

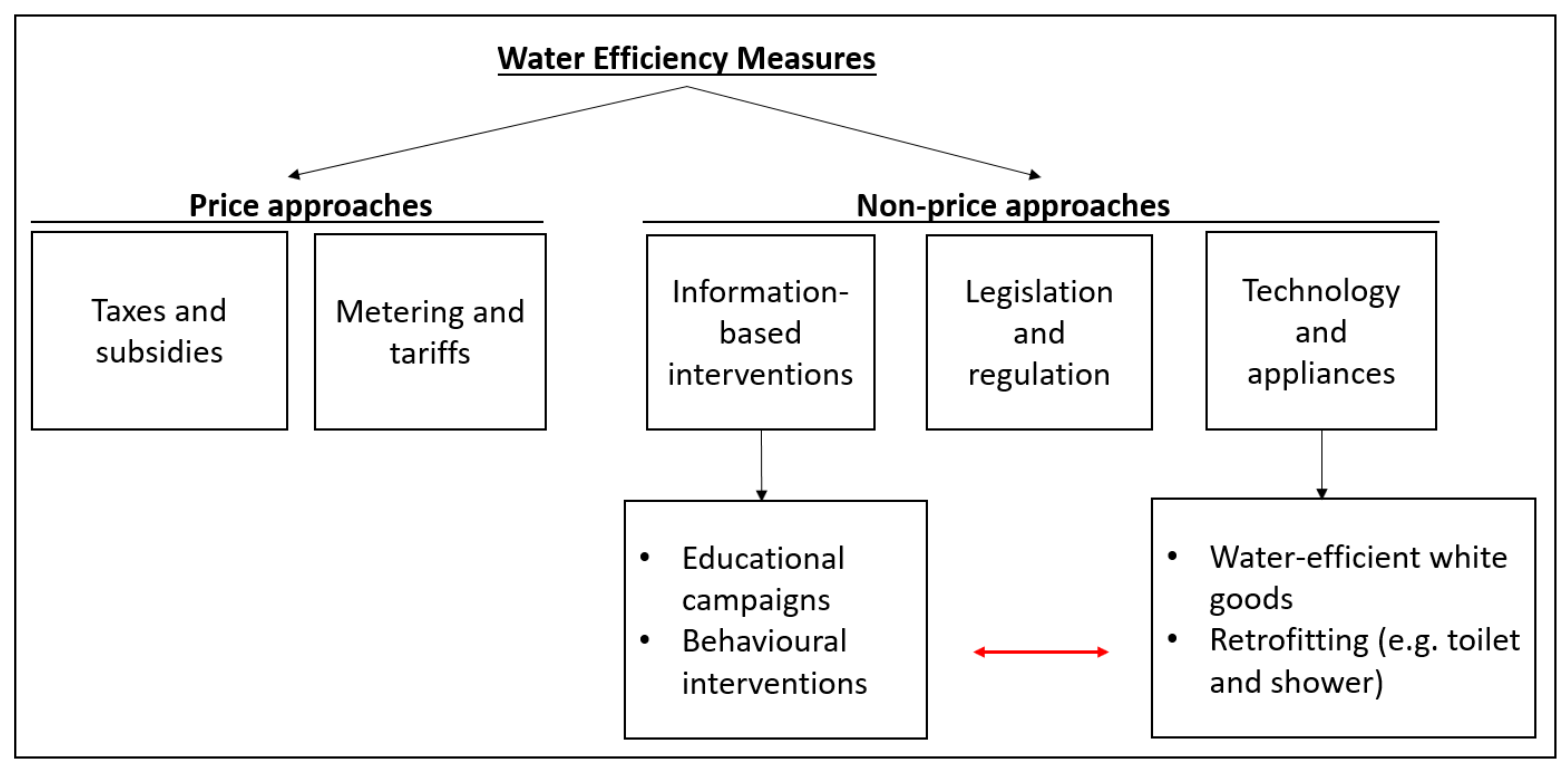

Figure 1. Water efficiency measures

In a broad sense, non-price information-based interventions refer to activities that aim at influencing the decision-making of individuals or groups to a particular direction - in this case to become more water efficient - through providing them with some types of information. In particular, trials of more targeted or personalised information provision, such as consumption feedback, have increasingly emerged as an alternative to more traditional educational campaigns (Lede et al., 2019), both because conceptually they tend to concern the specific 
beliefs of individual households on water (Corral-Verdugo et al., 2003), and empirically randomised controlled experiments are an established research tool that allows empirical evaluation (see e.g. Allcott, 2011). A carefully designed and implemented trial can thus capture the causality between the intervening information and the outcome, e.g. reduction in water consumption.

The information types used in an intervention can vary. As we will explain further in later sections of this paper, among different social policy fields, many trials of information provision are designed with direct insights from behavioural economics and social and environmental psychology, notably social norms, and are sometimes referred to as (information-based) behavioural interventions in academic literature (e.g. Allcott and Rogers, 2014). Behavioural interventions can be compared to other types of information provision by theoretical underpinnings and channel(s) through which they may influence households' consumption (Ferraro and Price, 2013).

Our motivation of examining information-based interventions carried out in the water sector in England and Wales is of several-fold. First, UK water consumers generally have a lack of knowledge on water resources, and their own water consumption and tariffs (Waddams and Clayton, 2010). As summarised in Lu et al. (2019), the low level of engagement may plausibly be due to that 1) the UK has a temperate climate and is not typically perceived as drought-prone; 2) water bills are typically small relative to household income and thus attract little attention. The share of water bill over income was around $1.5 \%$ for households in the third income quintile between 2000-2009 (Levell and Oldfield, 2011); 3) many households have an unmetered water supply. This context suggests both the urgent need and the scope for households to become more water-efficient through becoming better informed and prompted.

Second, water efficiency has been identified as an area of key challenge and priority in England and Wales following water companies' 2019 Water Resources Management Plans (WRMPs) (Ofwat, 2018). It is therefore increasingly pertinent to gather robust evidence on and cost-benefit analyses of not only water efficiency projects at their aggregate levels, but also the relative effectiveness of individual measures used. However, while there is enthusiasm in the water sector to influence households' decision-making via information provision, such as behavioural interventions (Ofwat, 2011; Lewis, 2016), and randomised controlled experiment is a practical means for implementation and evaluation, significant challenges and evidence gaps have been identified, as stated in the quote below

"All the literature suggests that UK water companies are now providing information to customers as part of water efficiency initiatives... the literature gives little detail about the way that information is provided and whether or how the nature of information provision changes the outcome" (Defra, 2018, p.72).

This suggests a clear lack of experience of information-based interventions, from conceptual framework and design, to implementation and evaluation.

Third, although robust evidence concerning information provision to influence household behaviour in the UK water sector is scarce, there is growing experimental evidence from other locations, notably the US (Ferrao and Miranda, 2013; Ferraro and Price, 2013), and from other sectors, such as consumer finance (Bertrand et al., 2010), energy (Allcott, 2011) and tax 
compliance (Larkin et al., 2018). Hence, there are learnings on offer that may be helpful to deal with the challenges mentioned above.

In this paper, we seek to understand the key barriers of conducting effective informationbased interventions in the water sector in England and Wales and the associated implications, which matter for a "step change in ambition for water efficiency" (Ofwat, 2018). "Rachel Fletcher, CEO of Ofwat, believed that the 2019 draft water resource management plans (WRMPs) published by water companies were 'really lacking in ambition' on the demand side, with 'quite low ambitions around reducing per capita consumption, even over a large number of years'. She considered that 'there are really huge opportunities for the companies to do more'..." (House of Commons, 2018).

Reviewing water companies' WRMPs 2019, the relevant literature and policy reports (e.g. Waterwise, 2015; Defra, 2018; Ashton et al. 2015), we find that while information-based interventions, especially behavioural interventions, have been recognised as a potentially useful means to influence household water consumption in England and Wales (Ofwat, 2011), and have typically accompanied retrofitting for the past decade, they have been given little dedicated consideration for their relative contribution towards end water savings. For the very few projects that had the intention to capture the effects of information provision, weak design and the practical obstacle of a lack of metering prevented robust evaluation.

The lack of intention and weak design may be explained partially by the confusion over various intervention types, and subsequently, the lack of understanding of the need to distinguish between different intervening components and their respective effects. In particular, there is confusion over 1) structural changes driven by fitting in water-efficient devices; 2) behavioural changes driven by fitting in water-efficient devices; and 3) behavioural changes driven by information provision, when retrofitting and information are used in combination, e.g. during a home visit. Psychology distinguishes between two types of water conservation behaviour: efficiency behaviours and curtailment behaviours (Russell and Fielding, 2010). In this context, 1) falls under the former category whereas 2) and 3) fall under the latter. This is evident from Defra (2018)'s final key conclusions in its rapid evidence assessment, where the lack of clear framework to link as well as to distinguish between different intervening components and their effectiveness represents a major concern. This paper seeks to alleviate the concern by providing a clear explanation of behavioural changes driven by information provision.

In contrast to that of England and Wales, the international experience of using information, especially behavioural interventions in water efficiency and conservation has demonstrated the attractiveness and power of taking full advantage of this instrument; it has gone further to evaluate alternative information types. In some other sectors, carefully crafted behavioural interventions have been proven cost-effective (Allcott and Rogers, 2014). The relevant literature offers guidance on how to optimise design and implementation, based on which we provide a clear agenda for future research/interventions, with the purpose of designing information-based interventions that can effectively enhance water efficiency and can be costeffectively implemented at large scale. 


\section{Non-price water efficiency evidence in England and Wales}

\section{Overview}

Encouraging water efficiency in household consumption is not new in the water sector in England and Wales. Ofwat (2011) discusses three different ways to do so: Push (regulation), Pull (metered charge) and Nudge (behaviour intervention). Closely related to this paper is nudge, which, as recognised in that report, is rooted in behavioural economics. When designed to encourage metered households to save water, it mentions that nudge may take the form of personalised information provision, such as usage feedback and benchmarking with neighbourhood.

In practice, under non-price approaches, water efficiency has increasingly been pursed in the form of retrofitting programmes in England and Wales (Waterwise, 2009; 2011). Carried out by water companies, retrofitting usually involves installation of water efficient devices in a property, such as dual flush conversions, showerheads and tap inserts, provided that the household living there accepts the invitation/signs up to participate in the programme. It is done either through home visits by a competent person (e.g. a plumber or trained staff) or through self-installation by households who receive devices via post. In the latter case it may not be clear whether households actually self-install (in the correct way) the devices received.

While retrofitting is itself a technology-based intervention that aims at improving water efficiency and reducing consumption through upgrading water-using devices, the implementation of programmes, especially those done through home visits, provides opportunities for information-based interventions. In practice, a home visit usually includes an audit by the competent person who also draws the household's attention to water efficiency and provides technical advices on how to improve. For water companies, home visits also provide the opportunity to gather information on household occupancy, types of water-using appliances in the home, etc., which may inform further water efficiency projects.

Over the last decade, water companies in England and Wales carried out around 25 water efficiency projects, most of which were retrofitting programmes (Waterwise, 2015; Appendix 4 in Defra, 2018). Ashton et al. (2015) conduct statistical analyses on nine retrofitting programmes after applying some selection criteria. One of the programmes, H2Eco by Essex and Suffolk Water, has ten phases. Ashton et al. (2015) cover the first nine. Most selected programmes are found to have significantly reduced water consumption, with an average of 13.5 litres per property per day, but the variation in reduction across programmes is considerable. This leads to their conclusion that 1) suitably designed water efficiency projects will reduce water consumption, 2) it is important to consider evaluation at the design phase because total water saving of an efficiency project depends on the performance of individual intervening components.

\section{Information-based interventions}

While information-based interventions, such as information leaflets containing water saving tips, messages encouraging water efficiency, consumption feedback or eco-labelling, have been accompanying technology-based installation in almost all retrofitting programmes (Defra, 
2018), little practical emphasis has been placed on quantifying their contribution to the end outcome.

\begin{tabular}{|c|c|c|c|c|c|}
\hline \multirow{2}{*}{ Projects } & \multicolumn{5}{|c|}{ Feasibility of evaluating information-based interventions } \\
\hline & $\begin{array}{c}\text { Intention } \\
\text { of } \\
\text { evaluation }\end{array}$ & $\begin{array}{c}\text { Full } \\
\text { metered } \\
\text { data }\end{array}$ & $\begin{array}{l}\text { Clear } \\
\text { Conceptual } \\
\text { framework } \\
\end{array}$ & $\begin{array}{c}\text { Treatment } \\
\text { control }\end{array}$ & $\begin{array}{l}\text { Consistency } \\
\text { in } \\
\text { information }\end{array}$ \\
\hline $\begin{array}{l}\text { 1. Save Water } \\
\text { Swindon, Thames } \\
\text { Water, Waterwise } \\
\text { and WWF } \\
\text { (Waterwise, 2012) }\end{array}$ & No & No & No & Yes & Not known \\
\hline $\begin{array}{l}\text { 2. Twerton, Wessex } \\
\text { Water } \\
\text { (Ashton et al., 2015) }\end{array}$ & Yes & No & No & Yes & No \\
\hline $\begin{array}{l}\text { 3. Challenge } \\
\text { Twenty:12, Essex } \\
\text { and Suffolk Water } \\
\text { (Ashton et al., 2015) }\end{array}$ & Yes & Yes & No & Yes & Yes \\
\hline $\begin{array}{ll}\text { 4. } & \text { H2eco Phase 10, } \\
\text { Essex and Suffolk } \\
\text { Water } \\
\text { (Essex and Suffolk } \\
\text { Water, 2015) }\end{array}$ & Yes & No & No & Yes & Yes \\
\hline $\begin{array}{l}\text { In-group norm } \\
\text { recruitment for Bits } \\
\text { and Bobs, Anglian } \\
\text { Water } \\
\text { (Lede and Meleady, } \\
\text { 2019) } \\
\end{array}$ & Yes & Yes & Yes & Yes & Yes \\
\hline
\end{tabular}

Table 1. Projects that consider evaluating information-based interventions

Defra (2018) is the most recent comprehensive assessment of evidence on water efficiency and behavioural change in the UK, in which a robust methodology of identifying and filtering the existing evidence base is specified. Ashton et al. (2015) is the only study offering statistical analysis of a number of water efficiency projects in the UK, where a set of selection criteria has been applied, such as availability of raw data and size of the project. Therefore projects included by these two studies are most likely to be suitable for further analysis. Using the lists in these two studies, we review each retrofitting programme for its design and implementation, to assess eligibility for robust evaluation. The five criteria considered, as shown in Table 1, are:

- Intention of evaluation: whether the project report includes evaluation of information provision as one of the research questions;

- Full metered data: Whether households involved in the intervention have metered water supply;

- Conceptual framework: whether the project report develops clear underlying assumptions about what influences water consumption behavioural;

- Treatment control: whether there is an appropriate treatment design, including a proper baseline, based on which the effects of information provision can be elicited; and 
- Consistency in information: whether the information provided to households in different treatments is consistent with treatment design so that the effects of information provision can be elicited.

We find only four (projects 1-4 in Table 1) that either were designed with the intention to quantify the effectiveness of information provision, or had designs that would have made evaluation theoretically feasible to some limited extent. Note that this differentiates the four projects from those that completely neglected the role of information provision in evaluation (and hence not included in Table 1), but it is not to suggest all four projects had robust design or evaluation. In fact, among all reviewed, project 4 (Essex and Suffolk Water, 2015) is the only one with a proper design for evaluating information-based interventions.

In addition, we include one project undertaken by Anglian Water and academic researchers (project 5 in Table 1, Lede and Meleady, 2019). As far as we are aware, this is the only study investigating information as the sole intervening component, and not in conjunction with any others, using a large sample size of over 2000 households. This project focused on a behavioural intervention using social norm messages, and measured its effectiveness on increasing sign-up rates to a retrofitting programme.

Table 1 provides examples for our discussion and help to identify the key barriers of conducting effective information-based interventions in the water sector in England and Wales, which we move on to next.

\section{Understanding key barriers}

Our main observation from reviewing the relevant evidence is that in England and Wales there is a clear omission of the dedicated role of information provision in contributing to the overall effectiveness of water efficiency projects where water-efficient devices were also installed. This indicates that many opportunities of generating data to quantify the effectiveness of information-based interventions may have been missed.

\section{$\underline{\text { Key barrier } 1}$}

Behind this observation, the first key barrier is the lack of understanding of the need to distinguish between different intervening components and their respective effects. For example, project 1 in Table 1 (Waterwise, 2012) had a treatment design that allowed comparisons between retrofitting done through home visits and self-installation. Whilst one may expect information provision in home visits to have explained some of the difference in outcomes between treatments, there is no explicit discussion in project evaluation in relation to this (Defra, 2018). This indicates that project 1, just like projects that are not included in Table 1, had no intention to study the role of information-based interventions.

Perhaps because all changes in household behaviour can be generically called behavioural changes, and that information provision has been seen as an integral part of retrofitting, there is confusion over

1) Structural changes driven by fitting in water-efficient devices;

2) Behavioural changes driven by fitting in water-efficient devices; and

3) Behavioural changes driven by information provision. 
As a consequence, it appears increasingly unclear what a behaviour/behavioural change approach to water efficiency actually refers to. It gets even worse when the term behaviour/behavioural change approach to water efficiency is casually and wrongly used interchangeably with the term behavioural economics approach to water efficiency. The latter is not a generic term and has clear social and psychological underpinnings, which we will discuss in the section "Understanding conceptual framework". Since changes driven by having water-efficient devices installed can be different in nature from changes driven by waterefficient messages, replacing the generic label with more specific definitions is the first step to separate out effects from different mechanisms (e.g. recall Figure 1). While it is common and usually helpful to combine alternative interventions to pursue water efficiency, understanding the nature and effectiveness of each component is crucial in establishing the most efficient and cost-effective approach to water efficiency.

\section{$\underline{\text { Key barrier } 2}$}

When there is the intention to quantify the effectiveness of information-based interventions, a second barrier in relation to conceptual framework arises as the lack of clear theoretical underpinnings of the intervening information. For examples, project 4 (Essex and Suffolk Water, 2015) involved retrofitting through home visits, in which half of the visits were "product only" whereas the other half were product plus "behavioural change information". Controlling for the effects of installing water-efficient devices, as well as the effects of face-to-face engagement via home visits, this treatment design allowed for a clear elicitation of the effects driven by "behavioural change information", which was estimated to be an additional saving of 7 litres per property per day (38\% more than "product only"). This is probably so far the most robust UK evidence quantifying how information provision contributes to water efficiency in a retrofitting programme, which to a great extent dealt with the first key barrier mentioned above.

The "behavioural change information" provided to households contained a long list of different types of information: information provided included water saving tips, water resources facts in relation to households (e.g. "did you know Essex is the driest county in the United Kingdom"), potential monetary savings when becoming more water-efficient, etc. The project report (Essex and Suffolk Water, 2015) does not explicitly discuss the conceptual framework behind each information type. While this does not affect gathering evidence on information provision as a whole, it makes it impossible to track the most effective information cues, and to understand the underlying mechanism, which would have contributed to the design of future information interventions.

Project 3 (Ashton et al., 2015) mentioned social norms as one channel through which the intervening cue "consumption benchmarking with neighbours" may influence household water consumption. However since this piece of information was sent out alongside other information and even with water-efficient devices if households ordered them, its effect was not elicited.

On the other hand, project 5 (Lede and Meleady, 2019) had a clear and specific conceptual framework based on social norms. It demonstrated that the inclusion of an in-group norm message in invitation letters (Figure 2) almost doubled the likelihood of households signing up to the retrofitting programme. 


\section{Norfolk Saves Water}

Norfolk is a water stressed area, with only a small gap between the amount of water available to us and the amount we all use. We know people in Norfolk care about the environment and saving water.

People from Norfolk are more likely to save water in their homes and gardens. It's why many people in your local community have signed up to receive water-saving devices through our free Bits \& Bobs giveaway. You can do the same!

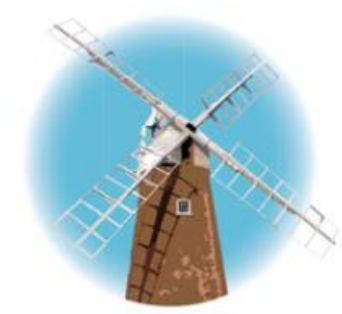

Figure 2. Behavioural intervention using in-group norm (Lede and Meleady, 2019)

Understanding the possible channels through which different information types may influence household water consumption is valuable for a robust design of intervention, as this is, in its essence, a question of what to be evaluated. It should aid the identification of the most cost-effective intervening cues, for examples behavioural theories offer insights on household responses (and heterogeneities in theirs responses). The clear gap in linking theories and designs of information-based interventions (Defra, 2018) may in fact explains the rather slow development.

\section{$\underline{\text { Key barrier } 3}$}

Once the first two barriers have been dealt with, the remaining tasks in design and implementation are largely technical details - sampling, choice of treatments, ways to frame information, consistency, etc. - everything that could potentially minimise noises and increase the chance of a robust evaluation. The lack of confidence, capacity and skills to take care of these technical details, however, has been suggested as a practical barrier for effective interventions in the water sector (Lewis, 2016; Defra, 2018).

\section{$\underline{\text { Key barrier } 4}$}

The evaluation of information-based interventions has been identified as another key barrier for the effective use of interventions. Limitations in terms of evaluating an intervention can largely be pre-empted by a clear intervening purpose, a robust design and careful procedures of implementation. Therefore dealing with the first three key barriers mentioned above facilitates the ease and robustness of evaluation. However, in the UK a practical obstacle for evaluation is the lack of metering. Recall Table 1, only projects 3 and 5 satisfied the condition of full metering for all households involved in interventions (Ashton et al., 2015; Lede and Meleady, 2019). In fact, this may be one justification of having neglected the role of information provision. In the absence of water meters, though not ideal, estimated savings could still be calculated based on the number and types of devices fitted in, whereas it is impossible to estimate savings from information provision. One alternative is to use district metering if the intervention concerns the whole area (Waterwise, 2009), but the potentially valuable household-level trends would still be missed. Another option is to use self-assessing surveys and ask households to note any change in their water use attitude and behaviour following the intervention. However, households' stated views may differ from their actual attitude and actions, and hence surveys should be a complement rather than a substitute for actual before and after consumption assessment. Given the constraint, one response might be to use information provision to encourage sign-ups to water meters, although the evaluation would not be direct water savings, but the sign-up rate to meters. 


\section{Dealing with barriers}

Drawing on insights from academic literature and practical applications, this section seeks to take a step further to fill in some gaps in understanding, clarify misunderstanding and suggest ways to improve, which to some extent help to deal with the key barriers presented above.

\section{Understanding conceptual framework}

Defra (2018) points out that very few interventions conducted by water companies explicitly set out to test a behavioural change, and such a gap may be partially due to the absence of theory. In addition, the theoretically sounding and intuitive mechanisms behind certain information types facilitate the understanding of why they are generally more effective in enhancing water efficiency than some other types. On the other hand, conflation of different mechanisms makes it more difficult to design an intervention as well as to optimise water efficiency practice.

In water-related information-based interventions, common types of information provided to households in field experiments include technical advice, descriptive norm message, socially comparative feedback and injunctive norm emoticon (e.g.:) (Lu et al., 2019). Technical advice such as water saving tips can drive changes through lowering transaction costs of information acquisition (Ferraro and Miranda, 2013), whereas behavioural changes driven by the other three information types are explained by the power of social norms and peer effect (Miller and Prentice, 2016), which are direct insights from behavioural economics and social and environmental psychology.

The use of behavioural interventions is rooted in behavioural theories: perfectly informed, rational, self-interested economic agents should not be affected by these information, but individuals with bounded rationality and other-regarding preferences may respond by changing their behaviours (see e.g. Thaler, 2016). Information-based behavioural interventions usually act as soft prompts for conservation behaviours without limiting households' options or imposing structural changes, which are in contrast to interventions using price, legislation and technology. This is similar to a 'mere' nudge (Thaler and Sustein, 2008) as discussed in Ofwat (2011). Back then, responses from UK academic researchers (e.g. Mehta and Waddams, 2011) have already pointed out the importance of distinguishing between information types with direct insights from behavioural economics, and those without.

\begin{tabular}{l|l}
\hline \hline Social norms & Examples \\
\hline Descriptive norm message & $\begin{array}{l}\text { "We all have to do our part to protect Cobb County's precious } \\
\text { water resources" (Ferraro and Price, 2013) }\end{array}$ \\
\hline Socially comparative feedback & $\begin{array}{l}\text { "You consumed more water than 73\% of your Cobb County } \\
\text { neighbors" (Ferraro and Price, 2013) }\end{array}$ \\
\hline Injunctive norm emoticon & "Your efficiency standing: GREAT (-):-(Allcott, 2011) \\
\hline \hline
\end{tabular}

Table 2. Examples of use of social norms in field experiments

Social norms refer to individuals' beliefs about what the majority of the others do or approve, and they can be qualitative, e.g. most people save water, and quantitative, e.g. on average people in England and Wales consume 141 litres of water per day. Normative beliefs have long been shown to influence behaviour (Cialdini and Trost. 1998) and Table 2 lists some 
examples of applying social norms in behavioural interventions for water and energy conservation.

More specifically, descriptive norm message seeks to convey a prosocial behaviour (or to reduce undesirable behaviour) through social influence. Socially comparative feedback provides a relevant and concrete benchmark that individuals can easily relate to and reflect. Injunctive norms encourage prosocial behaviour by showing social approval or disapproval, and emoticons $: ;$ and $: \circ$ are commonly used for this purpose. That is, even within the group of social norms, different messages can serve to trigger different behavioural cues, and thus may have different levels of effectiveness.

Compared to descriptive norm messages, socially comparative feedback might encourage more reduction in water consumption because in addition to general social influence, it provides a specific reference point that tend to induce stronger peer effect. For example, using data from a randomised controlled large-sample experiment in Atlanta in 2007, Ferraro and Price (2013) find socially comparative feedback to be significantly more effective in reducing household water consumption than descriptive norm messages and water saving tips. More specifically, the water conservation effect of households receiving information compared to households receive no information are $7.41 \%$ (for those receiving water saving tips), $28.74 \%$ (for those receiving water saving tips and descriptive norm messages) and 53.38\% (for those receiving water saving tips, descriptive norm messages and socially comparative feedback). However, descriptive norm messages can have the advantage of low cost, because information sent out is generic, and may therefore be cost-effective if targeting households who have no prior experience of social norm intervention.

Furthermore, while socially comparative feedback can encourage households with above average usage (i.e. the norm) to reduce usage, it may also lead to an unintended consequence where households using below the norm may use more. This so called "boomerang effect" (Clee and Wicklund, 1980) is clearly undesirable for the purpose of water efficiency. Schultz et al. (2007) find evidence of boomerang effect in the context of energy conservation in the US. That is, after households with below average consumption received the normative information regarding the neighbourhood average, they increased their energy consumption by $0.89 \mathrm{kWh}$ per day. In this context, injunctive norm messages such as smiley faces given to low water users may help alleviate or eliminate boomerang effect. By receiving smiley faces, households who consume below the norm know that their behaviour is socially approved and appreciated, and that they are not expected to increase usage. As demonstrated by Schultz et al. (2007), the use of injunctive norms eliminated the undesired boomerang effect.

\section{Optimising design and implementation}

Based on the underlying mechanisms and potential effects of different information types as explained in the previous section, this section discusses how implications from theories can inform the practical design and implementation of an intervention, with existing experimental evidence as examples.

First, it is common for an information-based intervention to use multiple types of information. It does not affect robust evaluation as long as treatments are appropriately designed. This can be done in two ways. First is to assign households to different treatments, 
and ensure households within the same treatment receive the same information type and households in different treatments receive different information types (e.g. Kurz et al., 2005). Second is to increase the number of information types received, one at a time, from one treatment to another. For example, households in treatment 1 receive one type of information, and households in treatment 2 receive two types of information. Either way, the total number of treatments needed will be the total number of information types to be included in the intervention, plus one, which is the baseline treatment in which households receive no intervention at all (e.g. Ferraro and Price, 2013; Fielding et al., 2013).

Second, the knowledge on households' awareness of water conversation in the intervening region is highly informative for the design. Households in a water stressed area are likely to have some awareness and knowledge about water conservation, and hence one might expect basic water-saving tips and generic descriptive norm messages to have limited effectiveness. On the other hand, for households with low level of awareness, as appears to be the case in the UK, those information types may have the scope to be cost-effective.

Third, while existing evidence suggests socially comparative feedback to be a promising information type in water an energy efficiency programmes, it is worth highlighting that households can have heterogeneous responses to socially comparative feedback. Ferraro and Miranda (2013) find wealthier households with higher water usage to be significantly more responsive to socially comparative feedback. In particular, high water users are found to be $94.1 \%$ more responsive than low water users. This may be because low water users have less scope to respond to any information, as their consumption is already low. Combining this observation with the boomerang effect, the implication for design is that it might be sensible to provide socially comparative feedback only to households with high water usage. More generally, future interventions should explore the relative effectiveness of different information types by household characteristics.

Fourth, another way to alleviate or eliminate the undesirable boomerang effect is to use injunctive norm together with descriptive norm or socially comparative feedback. Experimental evidence from energy efficiency programmes suggest such a combination to be desirable (Schultz et al., 2007; Allcott, 2011).

Fifth, the medium through which information reaches households may affect the outcome of behavioural interventions, which warrants further investigation. In the existing experimental evidence base of information-based intervention for water or energy conservation, information is typically communicated to households via post. Schultz et al. (2016) find that information sent by post to be more effective than that distributed online. Essex and Suffolk Water (2015) in the UK find communicating with households through door knocking to be inefficient.

Sixth, the long-run effects of behavioural interventions matter crucially regarding their cost-effectiveness. While most existing evidence focuses on the short-run effects of interventions, socially comparative feedback has been found to be persistent, although the size of the effect falls over time (Ferraro et al., 2011; Allcott and Rogers, 2014). It therefore would be valuable for future interventions to provide more and robust findings on long-run effects.

Finally, further design should consider the role of information endorser. So far, in the handful of water conservation experiments, the information received by households was mostly from a water company. The role of information endorser is currently unaddressed. However, 
the information endorser can potentially change the acceptability of information and the importance of it as perceived by households. In the UK there are debates over the appropriate degree of institutional coordination of water management between different levels of organisation. Hence, an agenda for future research could be the appropriate interplay between highlighting areas of national significance and using local relevance and sensitivities to engage consumers with social norms and everyday water conservation practices.

\section{Conclusion}

Given the increasingly critical water status in the UK, a 'twin-track' approach of reducing demand and increasing supply is advocated by stakeholders and carried out by water companies. As in many other countries, substantial resources have been devoted to water efficient technologies in the UK with the purpose of managing water demand. Water efficiency projects carried out by water companies over the last decade were primarily retrofitting programmes. However, water efficiency depends not only on technology but also on consumer behaviour and choices.

This paper suggests that a broader demand-side approach that includes information-based interventions, especially those draw on insights from behavioural economics, is merited. Behavioural interventions to consumer decision-making have been trialled in a number of social policy fields, and information provision has already been an integrated part of water efficiency projects in England and Wales. What has been missing, which led to the key evidence gap discussed in this paper, is "a concerted effort by researchers, policy-makers, and businesses to do the 'engineering' work of translating behavioural science insights into scaled interventions" (Allcott and Mullainathan, 2010). Such "engineering work" involves rigorous field experiments to assess the cost-effectiveness of applying behavioural interventions in water efficiency programmes. The existing evidence from other policy fields also appears to suggest that doing so would have high economic returns.

Following the call from key UK stakeholders, this paper summarises and discusses the key barriers regarding the current use of information-based behavioural interventions in water conservation in England and Wales. There is typically a lack of understanding of the need to distinguish between different intervening components and their respective effects in water conservation. Surprisingly low number of projects had the intention to quantify the contribution of information provision towards end water savings. For the very few projects that had the intention to capture the effects, weak design and the practical obstacle of a lack metering prevented robust evaluation.

We then seek to fill in some of the gaps in understanding by clarifying the conceptual framework of key information types used in conservation field experiments, where social norms are regarded as promising instrument. We suggest that further randomised control trials of behavioural interventions are a research priority. We provide a clear agenda for future research and policy interventions to build a robust evidence base that includes the conservation effects of different information types, how persistent those effects are, how they vary with household water use characteristic and socioeconomic characteristics, and the roles of information endorser and communication channel. 


\section{Reference}

Allcott, H. and Mullainathan, S. (2010) Behavior and energy policy. Science, 327(5970), 12041205.

Allcott, H. (2011) Social norms and energy conservation. Journal of Public Economics, 95, 1082-1095.

Allcott, H. and Rogers, T. (2014) The short-run and long-run effects of behavioral interventions: Experimental evidence from energy conservation. American Economic Review, 104(10), 3003-3037.

Ashton, V., Lawson, r., Marshallsay, D., Ponsonby, K. (2015) Water efficiency evidence base statistical analysis final report.

Bertrand, M., Karlan, D., Mullainathan, S., Shafir, E. and Zinman, J. (2010) What's advertising content worth? Evidence from a consumer credit marketing field experiment. Quarterly Journal of Economics, 125(1), 263-306.

Cialdini, R.B. and Trost. M.R. (1998) Social influence: Social norms, conformity, and compliance. In Gilbert, D.T., Fiske, S.T. and Lindzey, G. (Eds.) Handbook of social psychology ( $4^{\text {th }}$ ed., 2, 151-193). New York, NY: McGaw Hill.

Clee, M. and Wicklund, R.A. (1980) Consumer behavior and psychological reactance. Journal of Consumer Research, 6(4), 389-405.

Corral-Verdugo, V., Bechtel, R.B. and Fraijo-Sing, B. (2003) Environmental beliefs and water conservation: An empirical study. Journal of Environmental Psychology, 23(3), 247-257.

Defra (2018) Water efficiency and behaviour change rapid evidence assessment (REA) final report.

Essex and Suffolk (2015) $\mathrm{H}_{2}$ eco behavioural research (phase 10).

Ferraro, P.J. and Miranda, J.J. (2013) Heterogeneous treatment effects and causal mechanisms in non-pecuniary, information-based environmental policies: Evidence from a large-scale field experiment. Resource and Energy Economics, 35(3), 356-79.

Ferraro, P.J. and Price, M.K. (2013) Using nonpecuniary strategies to influence behavior: Evidence from a large-scale field experiment. Review of Economics and Statistics, 95(1), 64-73.

Ferraro, P.J., Miranda, J.J. and Price, M.K. (2011) The persistence of treatment effects with norm-based policy instruments: Evidence from a randomized environmental policy experiment. American Economic Review Papers and Proceedings, 101(3), 318-322.

Fielding, K.S., Spinks, A., Russell, S., McCrea, R., Stewart, R. and Gardner, J. (2013) An experimental test of voluntary strategies to promote urban water demand management. Journal of Environmental Management, 114, 343-351.

Kurz, T., Donaghue, N. and Walker, I. (2005) Utilizing a social-ecological framework to promote water and energy conservation: A field experiment. Journal of Applied Social Psychology, 35(6), 1281-1300. 
Larkin, C., Sanders, M., Andresen, I. and Algate, F. (2018) Testing local descriptive norms and salience of enforcement action: A field experiment to increase tax collection.

Lede, E. and Meleady, R. (2019) Applying social influence insights to encourage climate resilient domestic water behaviour: Bridging the theory-practice gap. Wiley Interdisciplinary Reviews: Climate Change, 10(1), 1-13.

Lede, E., Meleady, R. and Seger, C.R. (2019) Optimizing the influence of social norms interventions: Applying social identity insights to motivate residential water conservation. Journal of Environmental Psychology, 62, 105-114.

Levell, P. and Oldfield, Z. (2011) The spending patterns and inflation experience of lowincome households over the past decade. Institute for Fiscal Studies Commentary C119.

Lewis, H. (2016) What are the barriers to the use of behaviour change techniques in the UK water sector? King's College London.

Lu, L., Deller, D. and Hviid, M. (2019). Price and Behavioural Signals to Encourage Household Water Conservation: Implications for the UK. Water Resources Management, 33(2), 475491.

Mehta, J. and Waddams, C. (2011) Response to Ofwat's Push, pull, nudge - How can we help customers save water, energy and money?, Centre for Competition Policy.

Miller, D.T. and Prentice, D.A. (2016) Changing norms to change behavior. Annual Review of Psychology, 67, 339-361.

National Infrastructure Commission (2018) Preparing for a drier future - England's water infrastructure needs.

Ofwat (2011) Push, pull, nudge - How can we help customers save water, energy and money?

Ofwat (2018) Draft water resources management plans 2019: Overview of Ofwat's responses.

Riley, C. and Openshaw, R. (2009) Evidence: The social science of encouraging water efficiency.

Russell, S. and Fielding, K. (2010) Water demand management research: A psychological perspective. Water Resources Research, 46(5), 1-12.

Schultz, P.W., Nolan, J.M., Cialdini, R.B., Goldstein, N.J., and Griskevicius, V. (2007) The constructive, destructive, and reconstructive power of social norms. Psychological Science, $18,429-434$.

Schultz, P.W., Messina, A., Tronu, G., Limas, E.F., Gupta, R. and Estrada, M. (2016) Personalized normative feedback and the moderating role of personal norms: A field experiment to reduce residential water consumption. Environment and Behavior, 48(5), 686-710.

Thaler, R.H. (2016) Behavioral economics: Past, present, and future. American Economics Review, 106(7), 1577-1600.

Thaler, R.H. and Sustein, C. (2008) Nudge. Improving decisions about health, wealth and happiness Penguin Book, New York, NY.

House of Commons (2018) Regulation of the water industry. Eighth report of session 2017-19 
Waddams, C. and Clayton, K. (2010) Consumer choice in the water sector. Centre for Competition report published by Ofwat as part of Future Regulations project.

Waterwise (2009) Water efficiency retrofitting: A best practice guide.

Waterwise (2011) Evidence base for large-scale water efficiency phase II final report.

Waterwise (2012) Save water Swindon phase 1 evaluation.

Waterwise (2015) Water efficiency today: A 2015 UK review. 